\title{
Some problems of emergency food aid for sub-Saharan Africa
}

\author{
Hans Singer*
}

\section{Food Aid: Disaster Cure and/or Prevention?}

Nobody feels happy with the way the Ethiopian and other SSA emergencies have been handled. The doubts extend all the way from whether the emergency could have been prevented or mitigated by timely preventive action, using the potential of food aid as a developmental tool rather than an emergency tool. In recent years emergency food aid has not absorbed more than 20 per cent of total food aid (in terms of cereals two million tons out of 10 million tons). Although it must be anticipated that in the immediate future this percentage will be much higher - perhaps as much as 40 or 50 per cent - much food aid will remain to be directed to broader developmental purposes: balance-of-payments support, structural adjustment support, food for work and other development projects, support for human capital such as child feeding, school meals, etc. The question inevitably is whether some of this 80 per cent of past food aid could have been more successfully directed towards prevention of the kind of disaster we are now witnessing.

Next in line is the question of earlier warning of impending famine. More or less predictably, almost every agency and other institution involved in food aid, as well as recipient governments, now claims that they gave advance warning of impending famine but were not listened to. One can be slightly sceptical of some of these claims now - if everybody knew in advance and warned each other in advance, why then was there so little action in advance? There are answers to this question: perhaps everybody knew but waited

* This contribution is based on the proceedings of the Third IDS Food Aid Seminar on Food Aid and Emergencies held at the IDS 10-13 December 1984. The seminar was directed jointly by E. Clay and H. W. Singer. The article does not represent any kind of agreed report of the proceedings of this seminar, now published as Discussion Paper 206, IDS, Sussex, 1985 ('Food Aid and Emergencies', Edward Clay and Elizabeth Everitt, eds.). for the other to take action; or perhaps the knowledge was there but the political will to act was not: or perhaps the knowledge was there but the administrative capacity or the budgetary or legal resources needed for quick action were not, etc., etc., Be that as it may, here is certainly an agenda for the future. How can we get timelier and better co-ordinated action on such warnings? On what indicators or data should early warning be based? Who should be charged with the responsibility of issuing early warning and how should such early warnings be disseminated? There are many questions here to which there are no easy answers, but there is now general agreement that something must be done to improve things. At the IDS seminar many ideas and suggestions were put forward which cannot be discussed in detail here.

The voluntary agencies or NGOs, in particular, are among the claimants that they are in a better position than governmental agencies to have early warning of impending disasters; that in fact they issued such early warnings but were not listened to by the governments. This claim would be worth some impartial investigation now since it might help to provide guidance for prompter action in the future. Some NGO representatives would put it: 'We have the knowledge but do not have the resources to take action on the scale required; you (the governments) have the resources but lack the knowledge'. There is some truth in this, and certainly one problem is to marry the knowledge (wherever it may be) with the resources (wherever they may be).

The question of earlier warning also raises the question of the indicators or type of information needed. This came up frequently in the seminar. There is a broad consensus on the type of data that are useful: they obviously include rainfall data, crop monitoring, data on seeding and planting, data on population movement and specifically rural/urban migration, local stock movement, rising local food prices and falling prices of livestock and other assets which people anticipating famine try to sell, nutritional status of children and other vulnerable groups, etc.

IDS Bulletim. 1985. vol 16 no 3. Institute of Development Studies. Sussex 
Advance agreement on the relative weight to be given to these different indicators and the relative effort to be devoted to their collection and dissemination is perhaps less important than the collation of all possible data for any given situation and relevant local areas. Normally a really systematic effort will require the collaboration of the local government, and this immediately raises the kind of political problem discussed in the next paragraph. Data for Africa of the normal macro or micro economic type are notoriously scarce and unreliable; it is all the more important that a concentrated effort should be made to produce reliable data more specifically directed to the early signs of impending famine.

\section{The Politics of Early Warning}

We have just referred to the political problems involved. The local government, for various reasons, may not wish early signs of a famine to be made known or disseminated. In such cases, is it neo-colonialist to go over the head of the national government? A negative answer to this question seems very tempting, but it must be remembered that subsequent action to supply food in time to starving people may depend on the collaboration of the local government which in turn may be put in question by disagreements on early warning signs. The situation can also be reversed: the local government may claim that a famine is coming in order to obtain additional food aid when in fact it ought to be able to deal with the situation by normal local distribution and normal policies. The important political dimension of food aid for SSA emergencies is illustrated by the fact that in all four worst cases, i.e. Ethiopia, Sudan, Chad and Mozambique, there are internal civil wars, rebellions and/or foreign incursions. The support of the local government may be necessary but in such situations is clearly not sufficient: how can one get food aid into areas not controlled by the local government and in which the local government may perhaps deliberately wish to starve out its opponents? Here clearly the NGOs are at a certain advantage, although the present situation does not suggest that they have much elbow room to utilise it. Furthermore, among the governmental aid programmes bilateral programmes have probably more opportunity as well as incentive to include rebellious areas in food aid, whereas the multilateral programmes by their constitutions are committed to deal with the legal government only.

The early information needed is of course not limited to impending famine requirements but must also extend to the supply side of food aid. What are the stocks available which can be drawn upon at short notice? Where are they located? Who controls them? Is there quick access to them? What is the logistic infrastructure for distribution as needed - and the term 'infrastructure' goes well beyond the obvious physical infrastructure of transport, roads, storage space, etc., extending also to institutional arrangements which again are partly governmental arrangements, raising once again the political problems already mentioned.

Early action has a.special premium attached to it. If the support can reach the people threatened by famine before they have sold their cattle, eaten their seeds, used up their food stocks and started tracking from their villages to the roads or camps or other areas in search of food, obviously rehabilitation will be possible and easier. Once the area is deserted it will be difficult to think in terms of getting back to 'normal' in the future. This does not rule out the possibility that in certain cases it may be the right policy to vacate settled areas and resettle the people in a more promising environment. In such cases a Machiavellian case could be made for delaying aid until people are on the move. But obviously we are on dangerous ground here: in most actual cases involved such Machiavellian policies would be motivitated by politics more than by 'clever' economics. In. any case, if resettlement seems indicated, there must be better ways than starving those to be resettled out of their present villages, and a famine is not a promising context for successful resettlement.

\section{Macroeconomics and Food Supply}

The general feeling at the seminar was that a good deal of information was in fact available which was not properly brought together and utilised. In particular, some of the more macroeconomic information such as that collected by IMF missions and to some extent also by the World Bank in connection with structural adjustment lending is very relevant. For example, the debt situation and prospects of debt rescheduling clearly have a major impact on the capacity of an African country threatened by famine to import food commercially. In turn, information on the food situation and matters relating to food aid should be more fully taken into account in the consortia and consultative group meetings usually chaired by the World Bank, and should also be available to IMF missions in making their recommendations. At present, matters relating to food aid are either entirely absent from the consortia discussions or grossly neglected - this is one aspect of the price we pay for the institutional separation of financial aid and food aid in the UN system, with the former handled by the World Bank and the latter handled by the UN/FAO/WFP. This does not make for the best use of total available resources in the fight against famine.

There is also plenty of scope for improved and better co-ordination in the assessment missions by food aid 


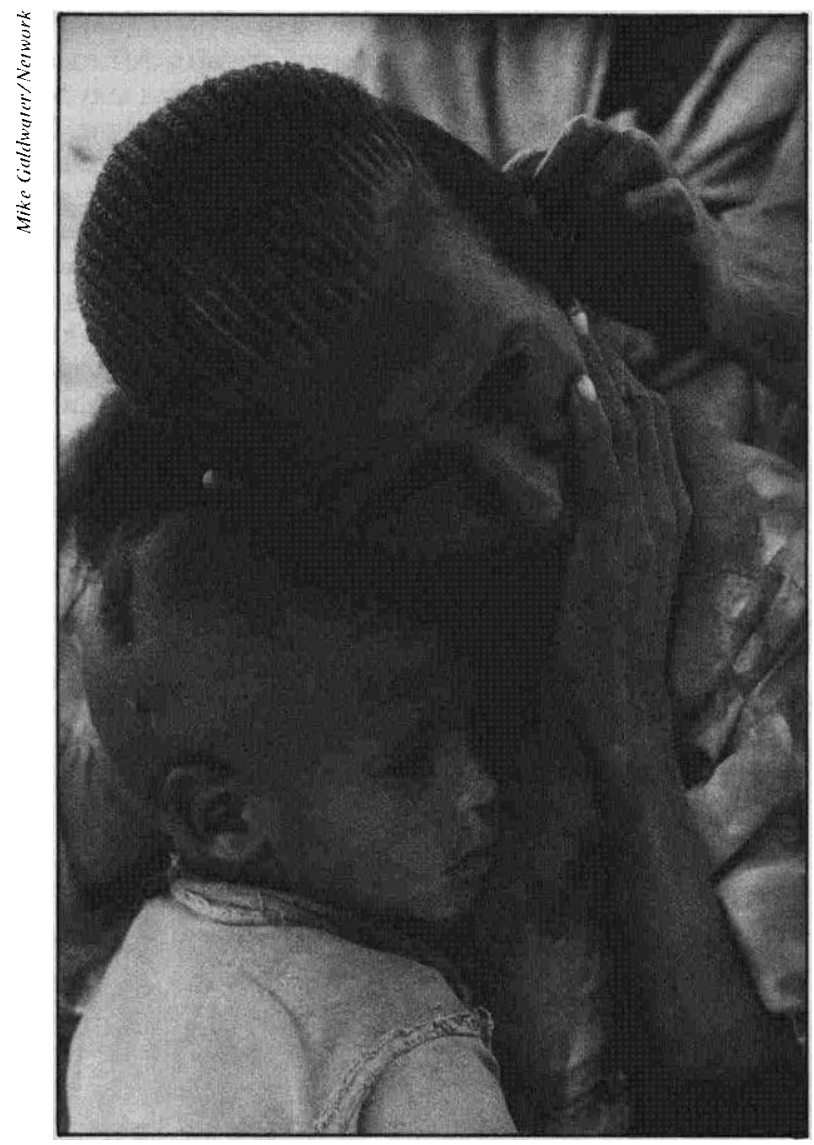

Mother and child anait food rations in Eritrea.

donors. Separate missions of this kind by individual donors place a great strain on the limited administrative capacity in the African famine countries, and divert harassed officials from their main object of trying to cope with the situation. Also, such separate assessment does not provide a favourable setting for proper co-ordination of donor action. Here again politics may intervene: some recipient countries may in fact prefer to deal with individual donors separately rather than face a solid phalanx of donors. Really effective co-ordination can only be achieved with the full cooperation of the recipient government, so better co-ordination among donors alone may take us a certain way but not all the way.

Since the voluntary organisations (NGOs) often have more detailed local knowledge it would be desirable to include them in information and assessment systems. On the other hand there is a risk of diverting them from their real operational objectives into providing information, attending meetings, etc. The central UN organisation for providing warning and information in disaster situations is the United Nations Disaster
Relief Organization (UNDRO) in Geneva. But while UNDRO has the means of rapid and wide dissemination of information it has practically no field staff of its own to collect and check information, and deals with sudden disasters rather than droughts and with non-food needs rather than food. In this respect the other two major information systems, the FAO early warning system and the US Department of Agriculture data system are better equipped but do not always agree with each other. So wherever we turn there are problems and difficulties.

\section{Action First: Then Detailed Assessment?}

One approach that found much favour in the seminar was the 'two-phase approach'. This means that in an impending disaster situation one does not start with time-consuming and difficult assessments leading to lengthy international discussions but with rapid action, preferably co-ordinated and certainly carefully arranged in advance on a stand-by basis. On a small scale, the Swiss rapid deployment system for quick stand-by action, including advance agreements with 
governments likely to be famine or disaster-prone was discussed, and recommended itself to many of the participants. This quick action would then provide a breathing space during which the best possible assessment of total needs, logistic problems, etc. should be made, laying the foundation for longer-term co-ordinated action. Quick initial action of course can be greatly facilitated by advance positioning of food earmarked for aid in emergencies. The largest food aid programme, the US PL480 programme, has in fact decided on such a policy of prepositioning stocks nearer potential famine areas (in this case in Niger and Kenya), but apparently this policy has run into some difficulties. There are obvious questions of political selection of depository countries, control of stocks, etc. The WFP has tried to solve such problems by doing its prepositioning outside the famine area itself, in Rotterdam and Singapore, ready for speedy despatch when and where needed.

Discussions in the seminar brought forward a number of issues in respect to which emergency food aid has proved to be inadequately conducted in the light of the present crisis in Africa. As an example the issue of emergency rations may be cited. It was found that the guidelines presently existing for the provision of emergency rations are unclear, resulting in different and often unsatisfactory levels of rations being provided. One of the suggestions emerging from the seminar was the convening as a matter of urgency of an expert group to draw up uniform guidelines for emergency rations. The proposed new guidelines should be pre-tested in ongoing emergency operations before they are brought to the attention of recipient countries and donor food aid organisations. Ultimately there could be an international agreement on emergency rations which could prevent future discrepancies. It is to be hoped that these and other matters arising from the seminar for further follow-up can be actively pursued in the future. The impartial evaluation of lessons to be learned from emergency food aid experiences in the different sub-Saharan African situations is another matter on which some understanding and agreement is urgently needed.

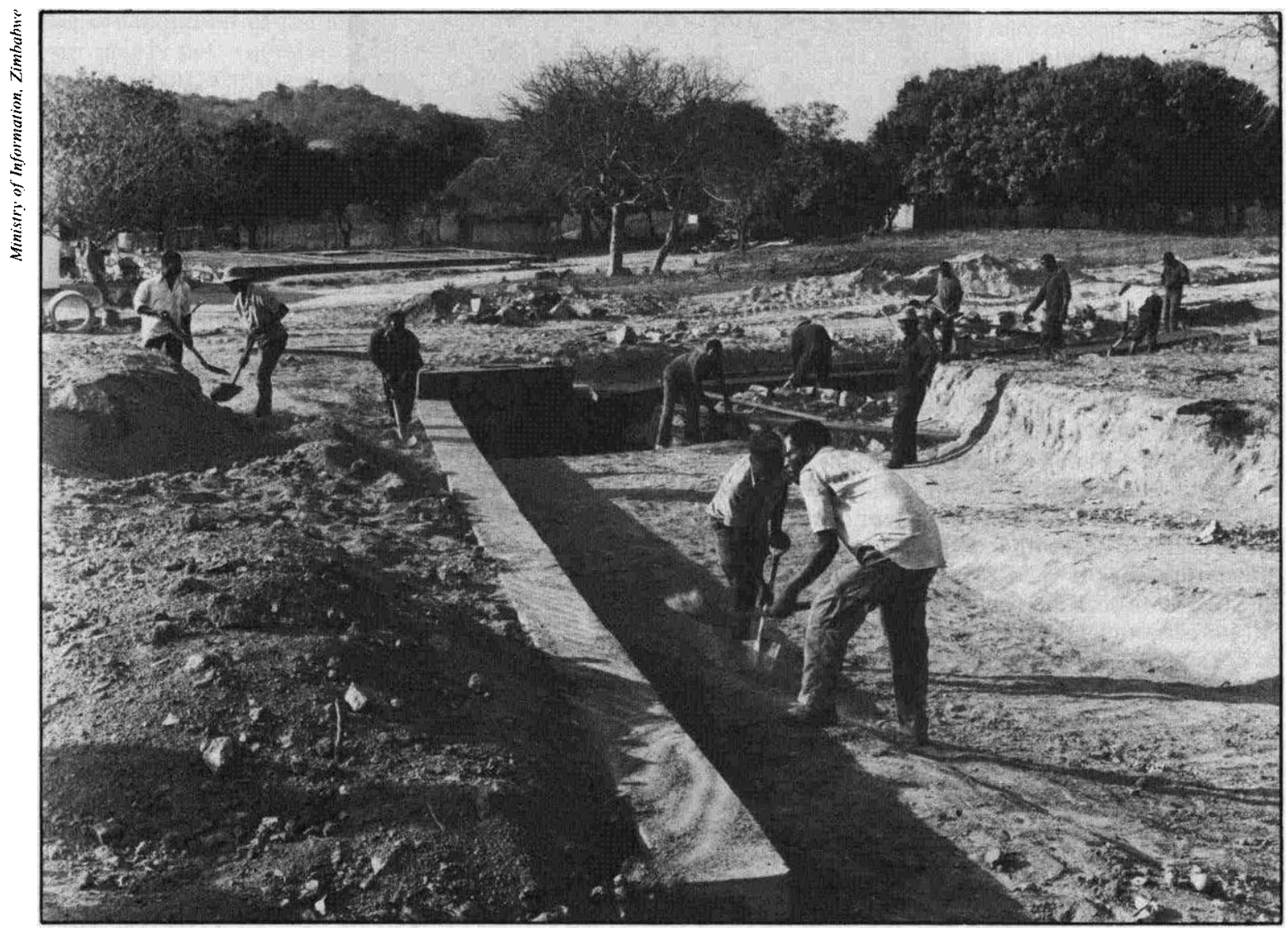

'Food for Work' schemes avert crises. 


\section{Resource and Allocation Constraints}

One great problem which recurs in all the discussions on emergency food aid in sub-Saharan Africa is that the emergency food aid requirements in that region are so enormous that they strain the resources available for total global food aid. This carried the risk on the one hand that legitimate emergency food aid needs will not be satisfied because of equally legitimate ongoing developmental or balance-of-payments programmes among more regular recipients of food aid in other regions, such as Egypt or Bangladesh. On the other hand, there is a risk that if such other perfectly legitimate developmental and balance-of-payments purposes of food aid are disrupted in order to cover the emergency needs of sub-Saharan Africa, this may well lay the foundation for future emergencies in the affected countries - some of them much larger than most or all of the countries of sub-Saharan Africa.

The old division, whether conceptual, administrative or resource allocative, between emergency food aid and non-emergency or developmental food aid simply collapses in the light of the present African experience, and a new approach is needed. Proper emergency food aid which would include the timely prevention of emergencies as well as the reconstruction or rehabilitation period after the immediate emergency until a more normal situation is reached, would include many elements of what used to be defined as developmental or non-emergency food aid, as well as the emergency part. It is likely that a future division should not be so much in terms of emergency versus non-emergency food aid, but rather in terms of 'special' food aid needed in the SSA region versus more 'normal' food aid needed elsewhere. The 10 million ton volume and the corresponding UN target may be adequate for the latter category but should not be expected to cover the former category as well. In the case of the former category, i.e. the special needs of the SSA region, food aid should be administered and applied much more in co-ordination with financial aid and with technical assistance than has been the case in the past. The creation of the World Bank/IDA Special Fund for sub-Saharan Africa may provide an opportunity to remedy some of the consequences of the historical separation, within the UN system, of financial aid administered by the World Bank and food aid administered by the UN/FAO/ WFP. In that sense the crisis may perhaps present a new opportunity, as well as a desperate challenge. 